\title{
APLIKASI PENGELOLA KEUANGAN PRIBADI BERBASIS DESKTOP
}

\author{
Silvia Ratna \\ Fakultas Teknologi Informasi, Universitas Islam Kalimantan Muhammad Arsyad Al Banjari Banjarmasin \\ Email : silvia@fti.uniska-bjm.ac.id
}

\begin{abstract}
Abstrak
Dengan melakukan pengelolaan keuangan pribadi, tiap individu tahu akan tujuan yang ingin dicapai, sehingga tiap individu harus memanfaatkan pengelolaan sumber daya keuangan secara optimal untuk mencapai tujuannya. Selain itu, generasi sekarang juga kerap kali malas dalam mencatat biaya-biaya pengeluaran sehari-harinya karena harus mencatat secara manual di kertas. Maka dibuatlah aplikasi yang dapat membantu mencatat biaya-biaya pengeluaran ataupun pemasukan sehariharinya. Pada penelitian ini dilakukan pembuatan aplikasi pengelola keuangan pribadi berbasis Desktop. Dari hasil pengujian yang telah dilakukan, aplikasi ini dapat memberikan laporan baik pemasukan maupun pengeluaran yang cepat, tepat dan akurat. Pengguna juga dapat membuat tabungan sendiri dan dapat melihat kurs secara real-time. Dengan adanya aplikasi ini pengguna dapat mengelola keuangan pribadi untuk memanjemen pengeluaran dan pemasukan
\end{abstract}

\section{Kata Kunci: Aplikasi, Pengelola keuangan, Database, Borland Delphi}

\section{PENDAHULUAN}

Sistem Informasi adalah suatu sistem di dalam suatu organisasi yang mempertemukan kebutuhan pengolahan transaksi harian, mendukung operasi, bersifat manajerial dan kegiatan strategi dari suatu organisasi dan menyediyakan pihak luar tertentu dengan laporan - laporan yang diperlukan. (H.M.Jogiyanto, 2005)

Dinamika dan perubahan masyarakat yang semakin cepat seiring dengan perkembangan jaman dan teknologi sehingga memerlukan kualitas informasi yang akurat, cepat dan tepat. Teknologi informasi adalah salah satu contoh produk teknologi yang berkembang sangat pesat yang dapat membantu manusia dalam mengolah data serta menyajikan sebuah informasi yang berkualitas.

Begitu pula dengan pengelolaan keuangan pribadi yang mana sangat membutuhkan bantuan teknologi komputer. Karena kehadiran komputer dirasakan sangat penting agar memudahkan dan mempercepat suatu perkerjaan yang dilakukan, misalnya dalam pengelolaan keuangan pribadi yang mana dalam penelitian ini akan memberikan kemudahan dalam pengelolaan anggaran, pemasukan, pengeluaran dan juga pembuatan laporan, dimana selama ini masih belum menggunakan aplikasi.

\section{METODE PENELITIAN}

Metode yang digunakan dalam penelitian ini yaitu metode System Development Life Cycle (SDLC) dengan model Waterfall. Metode ini mempunyai keunggulan dapat menjamin aplikasi yang dibuat memiliki kualitas yang sangat baik karena pengerjaannya yang bertahap, selain juga menjamin dokumentasi aplikasi yang menjadi lebih mudah dan baik. Berikut tahapantahapan dari metode Waterfall (Pressman, 2010):

1. Analisa kebutuhan, tahapan ini adalah tahapan paling awal. Pada tahapan

ini akan ditentukan input yang diperlukan, proses yang dilakukan oleh

sistem dan output yang akan dihasilkan sehingga dapat ditentukan

kebutuhan dan hasil dari aplikasi.

2. Desain sistem, pada tahapan ini hasil dari analisa kebutuhan kemudian dirancang menjadi tampilan-tampilan yang akan mempermudah dalam penggunaan aplikasi.

3. Implementasi, pada tahapan ini hasil dari desain sistem diterjemahkan kedalam tampilan dan kode program.

4. Integrasi dan Pengujian, tahapan selanjutnya adalah integrasi yaitu penggabungan modulmodul menjadi sebuah aplikasi yang utuh, kemudian dari aplikasi tersebut dilakukan pengujian. 
5. Pemeliharan, tahapan ini adalah tahapan terakhir. Setelah aplikasi digunakan maka akan terdapat umpan balik dari pengguna atas pemakaian aplikasi, selanjutnya dilakukan pemeliharaan dan peningkatan aplikasi.

Pada metode Software Development Life Cycle (SDLC) saat aplikasi yang telah dibuat masih perlu peningkatan maka tahapan yang harus dilakukan kembali ke tahapan awal (analisa kebutuhan).

\subsection{Analisa Sistem}

Dalam membangun aplikasi ini diperlukan perencanaan yang baik agar dihasilkan sistem yang dapat berjalan maksimal, adapun Tahap perencanaan ini terbagi atas 2 yaitu:

a. Menentukan tujuan pembuatan aplikasi, yaitu memberikan kemudahan untuk melakukan pengelolaan keuangan.

b. Memanajemen peamasukan dan pengeluaran serta juga memudahkan dalam proses pembuatan laporan.

\subsection{Perancangan Sistem}

Proses perancangan aplikasi secara terperinci, dilakukan dimulai dari perancangan Database, Relasi Antar Tabel, Diagram Konteks, Data Flow Diagram (DFD), Rancangan Tampilan, Rancangan Laporan, Pembuatan Program

Pembuatan Sistem Informasi akademik ini dibuat menggunakan bahasa pemrograman Delphi dan MySql sebagai pengelola databasenya.

\subsection{Testing Aplikasi}

Pada tahapan ini, dilakukan pengujian terhadap sistem yang telah dibuat dengan menggunakan metode blackbox dan juga withbox, sekiranya setelah aplikasi dibuat tidak banyak yang error atau harus diperbaiki.

\section{HASIL DAN PEMBAHASAN}

\subsection{Rancangan Aplikasi}

Berikut rancangan Menu Aplikasi Sistem Informasi Keuangan Pribadi berbasis Desktop:

\section{Master}
a. Kategori
b. Hutang Piutang
c. Anggaran
d. Tabungan
e. Transaksi Berulang
f. Transaksi KAS
g. Kartu Kredit
h. Keluar

\section{Report}
a. Laporan Kategori
b. Laporan Hutang Piutang
c. Laporan Anggaran
d. Laporan Tabungan
e. Laporan Kas

3. Setting

4. Close

\subsection{Rancangan Database}

Database dibuat menggunakan database MySql dan diberi nama db_keuangan, berikut tabel-tabel yang terbentuk dalam perancangan database:

1. Tabel Kategori

2. Tabel Anggaran

3. Tabel Hutang

4. Tabel Tabungan

5. Tabel Detail Tabungan

6. Tabel Transaksi Berulang

7. Tabel Kas

8. Tabel Kartu Kredit

9. Tabel User

\subsection{Rancangan Tampilan}

\section{Form Menu}

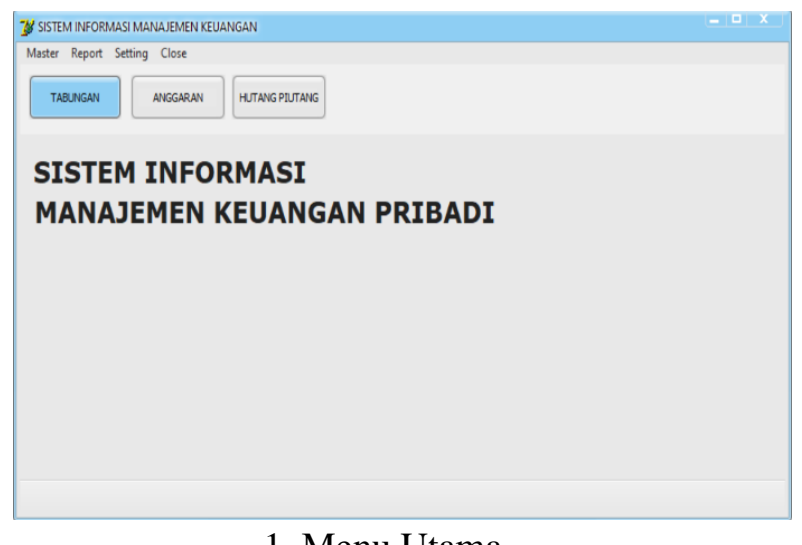

1. Menu Utama 


\section{Form Tabungan}

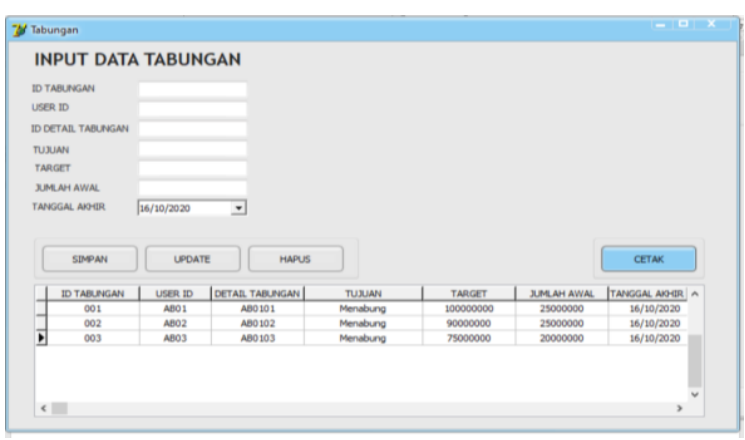

2. Tabungan

\section{Form Hutang Piutang}

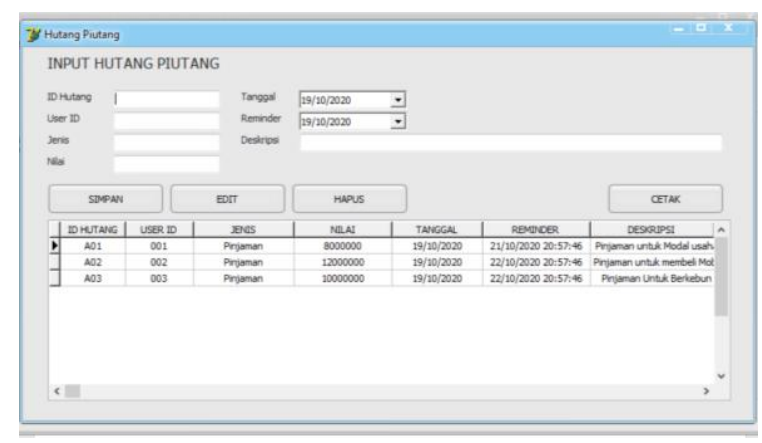

3. Hutang Piutang

\section{Form Anggaran}

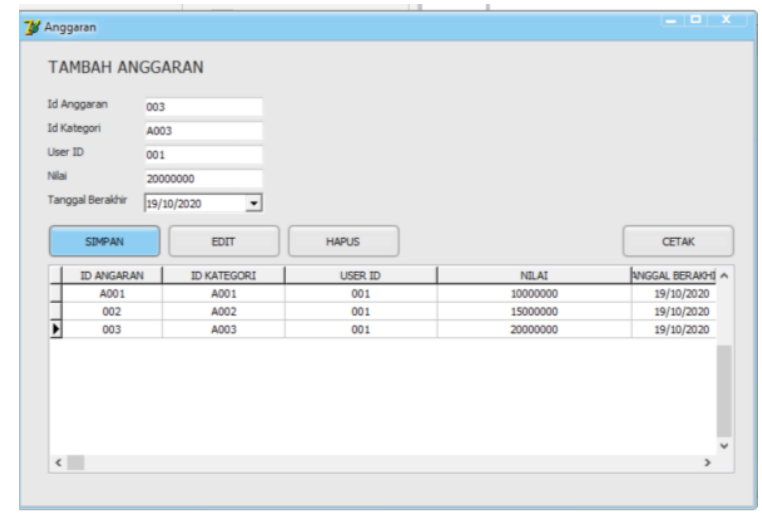

\section{Anggaran}

\section{Form Kas}

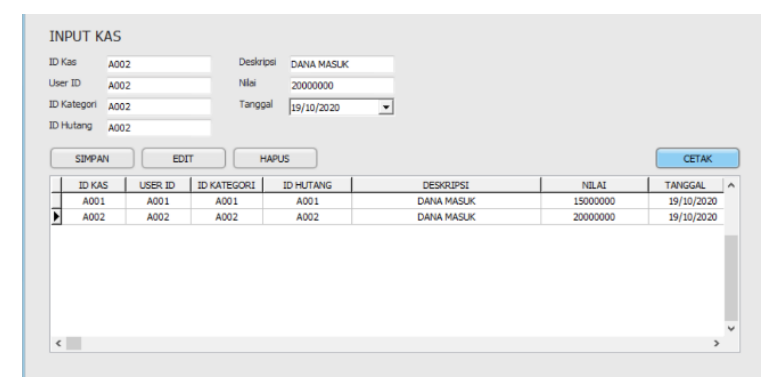

5. Kas
6. Laporan Tabungan

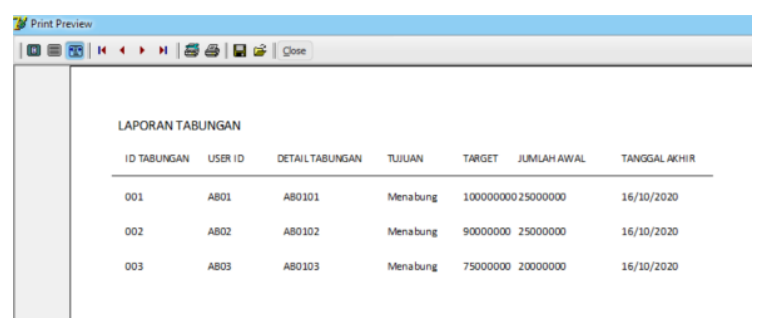

6. Laporan Tabungan

7. Laporan Hutang Piutang

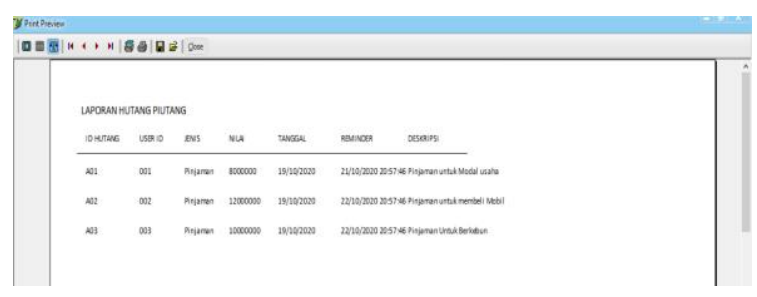

7. Laporan Hutang Piutang

\section{Laporan Anggaran}

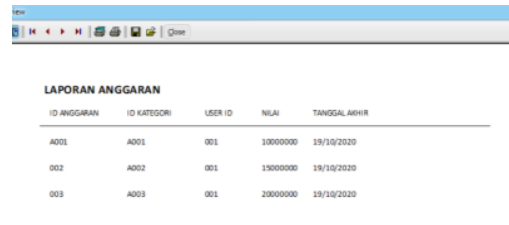

8. Laporan Anggarn

9. Laporan Kas

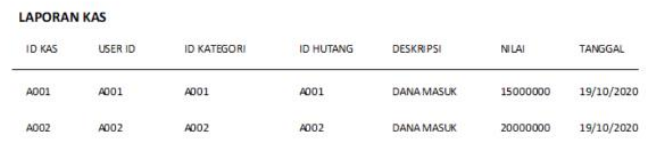

9. Laporan Kas

\section{KESIMPULAN}

Kesimpulan yang didapat dari penelitian ini yaitu :

a. Dengan aplikasi ini menjadi lebih mudah melakukan pencatatan pemasukan dan pengeluaran sehari-hari.

b. Mempermudah melihat laporan keuangan pemasukan dan pengeluaran

c. Proses pembuatan report/laporan menjadi lebih cepat, tepat dan akurat 


\section{DAFTAR PUSTAKA}

[1]Bahra, L. A. (2005). Analisis dan Desain Sistem Informasi. Yogyakarta: Graha Ilmu.

[2]H.M.Jogiyanto. (2005). Analisa dan Desain Sistem Informasi : Pendekatan Terstruktur Teori dan Praktik Aplikasi Bisnis. Yogyakarta: ANDI.

[3]Imelda, \& Erik. (2014). Perancangan Sistem Informasi Akademik Pada Sekolah Dasar Negeri Sukajadi 9 Bandung. Jurnal Sistem Informasi Akademik Vol. 3,No.4, 2.

[4]Jogiyanto. (2008). Metodologi Penelitian Sistem Informasi. Yogyakarta: Andi.

[5]Kadir, A. (2002). Pengenalan Sistem Informasi. Yogyakarta: Andi.

[6]Kristanto, A. (2003). Perancangan Sistem Informasi dan Aplikasinya. Gava Media.

[7]Nugroho, A. (2005). Analisis dan Perancangan Sistem Informasi dengan Metodologi Berorientasi Objek. Bandung: Informatika.

[8]Sugiyono. (2009). Metode Penelitian Kuantitatif, Kualitatif dan $R \& D$. Bandung: Alfabeta.

[9]Sutabri, T. (2012). Analisis Sistem Informasi. Yogyakarta: Andi.

[10]Yakub. (2012). Pengantar Sistem Informasi. Edisi 1. Yogyakarta: Graha Ilmu. 